\title{
PERFIL E PRINCIPAIS QUEIXAS DOS CLIENTES ENCAMINHADOS AO CENTRO DE ATENDIMENTO E APOIO PSICOLÓGICO AO ADOLESCENTE (CAAA) - UNIFESP/EPM
}

\author{
Teresa Helena Schoen-Ferreira \\ Dalva Alves Silva \\ Maria Aznar Farias \\ Edwiges Ferreira de Mattos Silvares ${ }^{\#}$
}

\begin{abstract}
RESUMO. Este estudo traça o perfil sociodemográfico do adolescente encaminhado ao serviço de psicologia do Centro de Atendimento e Apoio ao Adolescente (CAAA) do Departamento de Pediatria da Unifesp/EPM. A população, predominantemente na faixa de 13 a 15 anos de idade, igualmente distribuída do ponto de vista do sexo, cursava o Ensino Fundamental com defasagem escolar. Além disso, o presente estudo apresenta as queixas mais comuns do adolescente (dificuldades escolares) e a principal fonte de encaminhamento (médico hebeatra). A partir do levantamento, os autores discutem os dados comparando-os com outros estudos de mesma natureza. Comentam a necessidade de se trabalhar em equipe multidisciplinar e de se pensar em novos modelos de atendimento ao adolescente.
\end{abstract}

Palavras-chave: adolescência, saúde mental, Psicologia.

\section{SOCIAL-DEMOGRAPHIC PROFILE AND MAIN COMPLAINTS OF CLIENTS REFERRED TO THE CENTER OF PSYCHOLOGICAL ASSISTANCE AND AID TO ADOLESCENT - CAAA- UNIFESP/EPM}

\begin{abstract}
This study draws the social demographic profile of the adolescent referred to the service of Psychology of the Center of Assistance and Support to Adolescents (CAAA) of the Pediatrics Department of Unifesp/EPM with a population, consisting of 13 to 15 year old individuals, equally distributed by sex, attending elementary school with academic failure. The study shows the most common adolescents complains (learning problems) and the most frequent referrals (medical doctor). Based on this assessment the authors discuss several adolescent problems such as health, personal development, family and social environment with special focus on school progress and family relationship.
\end{abstract}

Key words: adolescence, mental health, adolescence.

\section{INTRODUÇÃO}

A Organização Mundial de Saúde - OMS considera adolescente o indivíduo que se encontra na segunda década de vida, ou seja, dos 10 aos 20 anos incompletos. Segundo a OMS, em 2000 um quarto da população mundial era de adolescentes. Destes, $80 \%$ viviam em cidades.

Sabendo-se do grande número de indivíduos nesta faixa etária, já em 1968, nos Estados Unidos, foi criada a Sociedade de Medicina do Adolescente; porém a primeira tentativa de se constituir um atendimento voltado exclusivamente a essa população ocorreu na Inglaterra, em 1884. Desde então, a adolescência tem motivado publicações científicas e criação de clínicas médicas.

No Brasil, a Medicina do Adolescente começou a ter maior importância a partir da década de 70, com a observação de que a mortalidade entre os jovens vinha aumentando consideravelmente naqueles anos, seguindo uma tendência inversa à das demais faixas etárias. De lá para cá, essa tendência tem-se agravado.

\footnotetext{
Universidade Federal de São Paulo/Escola Paulista de Medicina, Centro de Atendimento e Apoio ao Adolescente.

Endereço para correspondência: Universidade Federal de São Paulo/Escola Paulista de Medicina, Centro de Atendimento e Apoio ao Adolescente, Rua Botucatu, 715, 04023-062, São Paulo, SP. E-mail: adolescenc.dped@epm.br

\# Universidade de São Paulo, Programa de Pós-Graduação em Psicologia Clínica, bolsisita do CNPq..
} 
Estudos sobre levantamentos dos problemas que afetam a saúde do adolescente detectaram como mais comuns: gravidez indesejada, doenças sexualmente transmissíveis, acidentes com veículos a motor envolvendo o uso de álcool, fumo e drogas. Esses problemas, que, em sua origem, são mais comportamentais que biomédicos, levam a uma diminuição da qualidade de vida do hoje adolescente (amanhã adulto), quando não o levam à morte.

De acordo com o Seade (São Paulo, 1998), a taxa de mortalidade entre jovens residentes no Estado de São Paulo era superior à de países desenvolvidos e em desenvolvimento. Dentre as causas de mortalidade nesta faixa etária, aproximadamente $70 \%$ eram decorrentes de causas externas, isto é, acidentes, homicídios e suicídios.

É nesta fase que ocorre uma transição escolar, ou seja, a passagem do primeiro ciclo $\left(1^{\mathrm{a}}\right.$ a $4^{\mathrm{a}}$ série $)$ para o segundo ciclo ( $5^{\mathrm{a}}$ a $8^{\mathrm{a}}$ série) do Ensino Fundamental. Os estudantes passam de uma sala única, com menos alunos e uma só professora, para um ambiente maior, mais impessoal, com constante troca de professores e locais de estudo, além de um número maior de alunos. Esta mudança implica numa menor atenção individual e menor oportunidade de participação nas decisões da classe, acompanhadas de um grau de exigência maior, gerando, inclusive, uma queda no aproveitamento escolar e tendência à evasão escolar.

Esta evasão é um grande problema social, ainda mais por afetar especialmente os alunos de baixa renda e aqueles cujos pais têm menor nível de instrução. $\mathrm{O}$ abandono da escola limita as possibilidades futuras deste adolescente, que, possivelmente, terá mais dificuldades para conseguir e manter um emprego e provavelmente nele exercerá cargos de nível inferior ou mal-remunerados.

As causas que os próprios adolescentes elencam para terem deixado de estudar são: notas baixas, não gostar da escola, ter sido expulso ou suspenso ou ter de contribuir para o sustento da família. Para as meninas, além dessas, ainda aparece a gravidez ou casamento e o fato de sentirem que a escola não corresponde às suas necessidades (Papalia e Olds, 2000).

Siqueira e colaboradores (2002) observaram em seu estudo sobre adolescentes grávidas que a maioria deixou de estudar e não exercia atividade remunerada. Além disso, metade das adolescentes possuía o Ensino Fundamental incompleto.

Segundo Muñiz (2001), as dificuldades de aprendizagem e adaptação escolar apresentam 35\% das motivações para consultas pediátricas na fase dos 6 aos 24 anos e $45 \%$ dos atendimentos em saúde mental no mundo. Kimmel e Weiner (1998) consideram os problemas escolares e os problemas de comportamento aqueles que mais dificultam o desenvolvimento normal do adolescente e necessitam de atendimento especializado. Graminha e Martins (1994) afirmam que as dificuldades escolares se constituem no principal motivo da procura de atendimento psicológico para crianças.

Abandonar a escola pode estar relacionado com a falta de motivação, baixa auto-estima, falta de encorajamento parental, baixas expectativas por parte dos professores, treinamento inadequado para jovens que não pretendem ingressar na faculdade, além de problemas disciplinares, sem contar com os problemas relacionados à estrutura escolar, já sobejamente conhecidos.

Dados do Seade (São Paulo, 1998) mostraram que $18,1 \%$ dos adolescentes tinham abandonado o Ensino Fundamental e que $40 \%$ entre 15 e 17 anos de idade, no Estado de São Paulo, ainda cursavam alguma série do Ensino Fundamental, ressaltando o peso do atraso escolar, mesmo no estado mais rico da Nação.

No Anuário Estatístico do Brasil (Instituto Brasileiro de Geografia e Estatística, 1999), encontramos que a média de escolaridade da população com mais de 10 anos de idade, na Região Metropolitana de São Paulo, é de 6,8 anos de escolaridade, o que equivale ao Ensino Fundamental incompleto. É interessante destacar que, quando analisada apenas a população ocupada, esta sobe para 7,6 anos de escolaridade para o sexo masculino e 8,4 para o sexo feminino, numa média geral de 7,9 anos de escolaridade para ambos os sexos. Ainda observando esta região, temos $96,8 \%$ inseridos em escola, na idade dos 7 aos 14 anos - período de escolarização obrigatória. Na idade de 15 a 17 , esta taxa desce para $81,7 \%$; enquanto que, entre 18 e 19 anos, há apenas $50 \%$ dos adolescentes na escola.

A adolescência é a etapa do processo evolutivo que mais tem sido vista de maneira estereotipada (Schoen-Ferreira, 2001). Hoffman, Paris e Hall (1996), a partir de estudos sobre adolescência, destacam quatro mitos sobre esta etapa do desenvolvimento: 1) que a adolescência seja um período de instabilidade emocional (período de turbulência e tensão); 2) que os problemas que aparecem sejam próprios da idade e resolvidos com o amadurecimento do adolescente; 3) que a necessidade dos jovens de separar-se de seus pais resulte em conflitos intensos e hostilidades; e 4) que exista invariavelm um abismo entre gerações. Para Ungar (2000), os diversos mitos sobre esta etapa do desenvolvimento permitem que os adultos expliquem 
comportamentos inconvenientes dos jovens. Tal pensamento dificulta a realização de um diagnóstico diferencial sobre os verdadeiros sinais e sintomas da patologia que podem estar sendo desenvolvidos na adolescência.

\section{CENTRO DE ATENDIMENTO E APOIO AO ADOLESCENTE (CAAA)}

Em face dessas considerações, o Departamento de Pediatria e a Unifesp integraram recursos e esforços para o crescimento e melhoria do plano de assistência integral à saúde do adolescente e, em 1993, constituíram o Centro de Atendimento e Apoio ao Adolescente - CAAA.

Durante seis anos, o serviço realizou suas atividades no próprio ambulatório geral de Pediatria, por falta de local. Com isso foi se delineando uma equipe multidisciplinar, que passou a receber especialistas em Psicologia, Nutrição, Serviço Social, Fonoaudiologia, Psicopedagogia, entre outras especialidades.

A partir de 1997, o CAAA estabeleceu-se em um local próprio, aumentando não só a equipe que atua com os adolescentes mas também o número de atendimentos a adolescentes que passaram a procurar o serviço. Estes chegam ao centro através de alguma indicação externa (escola, amigos, centros de juventude) ou encaminhados por profissionais dos diversos setores do Hospital São Paulo.

Em 1993, quando foi criado, o CAAA registrava 232 adolescentes matriculados. Em 1997, quando adquiriu um local próprio, havia 368 adolescentes matriculados, verificando-se um aumento de 92 pacientes por ano. Em 1998 essa cifra já era de 564 adolescentes matriculados (com um aumento de 153,2\% no ano) e em maio de 2001 foram protocoladas 2700 matrículas (um aumento de 710 pacientes ao ano).

Destaca-se como principal objetivo do CAAA dar assistência integral à saúde do adolescente, em seus aspectos orgânicos, psicoemocionais e sociais, visando prevenir problemas decorrentes da insegurança e baixa auto-estima, para que possa atingir a idade adulta com saúde e prazer de viver.

O Serviço de Psicologia do CAAA elegeu como principais os seguintes objetivos para a sua atuação: 1 . dar assistência psicológica ao adolescente, dentro do programa de assistência integral do CAAA; e 2. produzir e transmitir conhecimentos sobre $\mathrm{O}$ desenvolvimento do adolescente.

Nesse sentido, o setor tem as mesmas características de um hospital-escola, haja vista seus objetivos de extensão e pesquisa acima arrolados.

\section{ATENDIMENTOS PSICOLÓGICOS EM HOSPITAIS-ESCOLA E CLÍNICAS-ESCOLA}

Vários estudos de avaliação diagnóstica foram realizados em hospitais-escola brasileiros, nos quais é feito um levantamento das características e necessidades dos usuários do hospital. Entre esses estudos encontra-se o de Dios e Silvares (1993), no qual foram estudadas as características sociodemográficas da clientela infantil do Setor de Higiene Mental de um hospital-escola, em São Paulo. Nele, ficaram evidenciadas as causas principais de procura pelo setor. Observaram ainda as autoras que a maioria dos clientes era do sexo masculino e tinha pais com nível primário de instrução. $\mathrm{O}$ encaminhamento ao Setor de Higiene Mental se deu, principalmente, através de outras clínicas do próprio hospital, e a queixa principal era mau desempenho escolar, seguido de comportamento agressivo.

Bernardes-da-Rosa, Garcia, Domingos e Silvares (2000) também caracterizaram a clientela com queixa de dificuldades escolares atendida em um Serviço de Psicologia de um hospital-escola. Embora a maioria fosse do sexo masculino, não houve diferença significante entre os sexos para a procura pelo serviço com este tipo de queixa. Observaram ainda as autoras que a maioria das crianças foi encaminhada por profissionais da saúde, embora a queixa principal tivesse sido a de dificuldade escolar. Houve uma tendência para o encaminhamento de crianças nos primeiros anos de escolarização. Os pais destas crianças apresentavam baixo nível de escolaridade.

Yehia (1994) observou que $16 \%$ dos encaminhamentos para o serviço de identificação de superdotados numa clínica psicológica eram realizados por médicos, demonstrando a importância deste profissional na identificação de outras questões que não saúde física. Dos clientes deste serviço, 79\% eram do sexo masculino, e a faixa etária dos 10 aos 14 anos - início da adolescência - foi a de maior clientela.

Em um estudo sobre a caracterização da clientela atendida na clínica-escola do Instituto de Psicologia da Puccamp, Carvalho e Térsis (1989) também observaram que os médicos são os que mais encaminham clientes (psiquiatra - 12,6\%; clínico geral e outras especialidades - 15,5\%). A faixa etária de maior procura foi a da adolescência, com 9,6\% de 11 a 15 anos e 9,7\% dos 16 aos 20 anos. Neste estudo, foi observada uma igualdade em relação ao sexo dos clientes.

Martins e Graminha (1994) consideram necessário identificar os motivos da procura de atendimento psicológico. Em seu estudo houve uma prevalência de queixas múltiplas, o que indica que, na maioria dos casos, os pais buscam ajuda psicológica 
para o filho quando percebem que este está manifestando diversos problemas.

Em um levantamento dos casos de crianças e adolescentes encaminhados para psicólogos do Serviço Público de Saúde, Cabral e Sawaia (2001) observaram que a maioria deles $(69 \%)$ apresentava queixas escolares. Outras queixas freqüentes eram enurese, encoprese, agressão ou abuso sexual.

Um estudo realizado por Graminha, Santos e Brandani (1987) observou que havia mais meninas em atendimento, apesar de a porcentagem de meninos necessitando atendimento psicológico ser maior.

$\mathrm{Na}$ primeira avaliação diagnóstica do CAAA, em 1999, feita por Aznar Farias e Medeiros, foram analisados 145 prontuários médicos do setor e observou-se que $60 \%$ dos pacientes eram do sexo feminino. A idade dos usuários variou entre 9 anos e 10 meses a 18 anos e 9 meses, sendo que $90 \%$ encontravam-se entre 12 e 16 anos. As principais queixas apresentadas aos médicos do setor foram: baixa estatura (15,6\%), dores crônicas $(14,4 \%)$, obesidade $(11,3 \%)$, problemas ginecológicos $(8,1 \%)$, problemas na relação familiar $(8,1 \%)$, queixas urinárias $(6,9 \%)$, e dificuldades escolares $(5,6 \%)$, entre outras, sendo que 23,1\% não apresentaram queixa alguma.

Como hipótese explicativa para esse quase um quarto dos prontuários não ter uma queixa anotada, levantou-se o fato de muitos adolescentes serem encaminhados ao CAAA pelo próprio Departamento de Pediatria para seguimento. Como este setor focaliza especialmente o crescimento e desenvolvimento do usuário, deu menos atenção às queixas comportamentais específicas na primeira consulta.

Todos os trabalhos arrolados anteriormente tinham por base o pressuposto de que para melhor atender à clientela faz-se necessário conhecer as características e necessidades dela. Muitos, como o de Graminha e Martins (1989), procuram, inclusive, a partir do estudo, propor um novo modelo para o atendimento psicológico. Como já haviam transcorrido mais de quatro anos desde o último levantamento diagnóstico do setor (CAAA) e como a primeira avaliação parecera incompleta em virtude da falta de focalização das queixas comportamentais, foi delineado o presente estudo, especificando o serviço de Psicologia.

\section{OBJETIVOS DESTE ESTUDO}

Assim, o presente trabalho teve como objetivos traçar o perfil sociodemográfico dos adolescentes encaminhados ao Serviço de Psicologia do CAAA e identificar as principais queixas apresentadas, a fim de oferecer melhor orientação à equipe de profissionais do setor e a elaboração de programas de atendimento que visem atender os adolescentes.

\section{MÉTODO}

\section{Participantes}

Participaram do presente estudo todos os adolescentes atendidos pelo Serviço de Psicologia do CAAA, de 1997 a 2000, num total de sessenta e um. Dentro dessa população situam-se os que podem ter sido atendidos uma única vez ou ter sido seguidos em atendimento psicoterápico ou psicopedagógico.

\section{Procedimento}

Foram levantados os dados dos prontuários dos participantes, seguindo um roteiro no qual constavam duas partes: uma relativa a dados sociodemográficos e a outra relativa às queixas trazidas na primeira entrevista psicológica.

As queixas apresentadas nos prontuários foram classificadas tendo como referência a lista de problemas de comportamento arrolados no Inventário de Comportamentos da Infância e Adolescência - versão brasileira do "Child Behavior Checklist" (CBCL), abrangendo 113 tipos de comportamento diferentes.

Os resultados foram agrupados de modo a fornecer informações sobre: a) frequiência de adolescentes atendidos por idade e sexo; b) escolaridade dos adolescentes; c) índice de repetência; d) número de adolescentes que trabalham; e) tipo de família dos adolescentes encaminhados; f) fonte de encaminhamento para o serviço de Psicologia; e g) queixa apresentada por idade e sexo.

\section{RESULTADOS}

Os dados sociodemográficos dos adolescentes atendidos pelo setor de Psicologia podem ser observados na Tabela 1 .

Tabela 1: Caracterização sócio-demográfica da população de adolescentes atendida pelo setor de psicologia do CAAA UNIFESP/EPM - de 1997 a 2000.

\begin{tabular}{lcccr}
\hline Sexo & Masc.: 33 & Fem.: 28 & & \\
\hline Faixa etária & 10-12: 19 & 13-15: 27 & 16-19: 14 & Sem dado: 1 \\
Escolaridade & Ens. Fund.: 46 & Ens. Médio 8 & Fora da escola: 2 & Sem dado: 5 \\
Repetência & Nenhuma: 28 & Uma: 6 & Duas ou mais: 18 & Sem dado: 9 \\
Tipo de família & Monopa-rental: 8 & Biparental: 41 & Outros: 7 & Sem dado: 5 \\
Exerce profissão & Não: 54 & Sim: 4 & Sem dado: 3 \\
\hline
\end{tabular}

Quanto à variável sexo do paciente atendido pelo serviço de Psicologia, observou-se um pequeno predomínio de um sexo sobre o outro, pois $54,1 \%$ eram do sexo masculino e $45,9 \%$ do sexo feminino.

A faixa etária de maior procura por ajuda psicológica foi de 13 a 15 anos, sendo que a idade média dos 
adolescentes atendidos foi de 12,6 anos. Isto se deve primeiro ao fato de que, apesar de o CAAA atender adolescentes a partir dos 10 anos, a faixa que vai dos 10 aos 12 anos incompletos também é atendida por outro setor do hospital, sendo que só aos 12 anos completos o paciente é encaminhado ao serviço específico de atendimento ao adolescente. E, em segundo lugar, como observado em outros estudos conduzidos em clínicas-escola, há uma maior procura por atendimento entre os indivíduos em idade escolar, especialmente entre aqueles que freqüentam o Ensino Fundamental.

Cabe ressaltar que a série escolar com maior frequiência de busca ao atendimento foi a $7^{\mathrm{a}}$, seguida da $6^{\mathrm{a}}$ série do Ensino Fundamental. Havia três adolescentes que freqüientavam uma classe especial. Em cinco prontuários não havia registro sobre a escolarização do adolescente.

Quanto à repetência escolar, 39,34\% já haviam repetido uma série escolar alguma vez, sendo que, destes, a maioria apresentava mais de uma repetência. Onze adolescentes ainda estavam cursando o primeiro ciclo do Ensino Fundamental. Um dos adolescentes já havia terminado o Ensino Médio. Havia 19 adolescentes com 15 anos ou mais, cursando o Ensino Fundamental, os quais já deveriam estar cursando a fase seguinte. Verificou-se que somente 8 (oito) adolescentes estavam cursando o Ensino Médio (13,11\% do universo).

A maioria dos adolescentes atendidos pelo setor de Psicologia do CAAA não trabalhava, sendo que 14 adolescentes tinham mais de 16 anos e já poderiam ter carteira profissional. Somente quatro trabalhavam e estes estavam cursando o Ensino Fundamental (um a oitava série; um a quinta série e dois a quarta série). Dois estavam com catorze anos e todos estavam defasados na relação idade-série escolar.

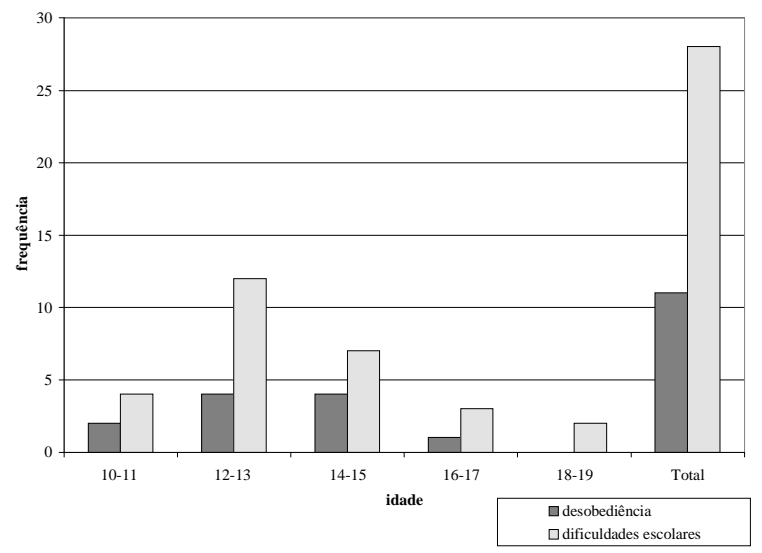

Figura 1: Freqüência das duas principais queixas motivo de encaminhamento dos adolescentes de acordo com a idade, ao serviço de Psicologia do Centro de Atendimento e Apoio ao Adolescente (CAAA) do Departamento de Pediatria da Escola Paulista de Medicina da Unifesp, referente ao período de 1997 a 2000.

Tendo-se como referência a lista de problemas de comportamento do CBCL, a queixa com maior prevalência foi a de número 61 - não vai bem na escola -, presente em
28 prontuários de pacientes. A segunda queixa na ordem de prevalência foi a 22 - é desobediente em casa -, que, somada à queixa seguinte, a 23 - é desobediente na escola, deixou a queixa "desobediência" abrangendo 11 pacientes, ainda em segundo lugar. Outras queixas dignas de nota foram: a 108 - faz xixi na cama, em relação a 4 adolescentes; a 10 - é agitado, não pára quieto, em relação a 4 clientes; e a número 55 - está gordo demais, também em relação a 4 pacientes. A estas queixas identificadas podem somar-se outras, que, em alguns clientes, incluíram abuso sexual e gravidez. A Figura 1 ilustra as duas queixas mais freqüentes, desobediência e dificuldades escolares, em função da variável idade.

A Figura 1 demonstra que a queixa escolar esteve presente em todas as faixas etárias, prevalecendo dos 12 aos 13 anos e diminuindo sua freqüência a partir dos 14 anos. A queixa desobediência, tanto em casa quanto na escola, apareceu com maior freqüência entre 12 e 15 anos, diminuindo a partir daí e não aparecendo no final da adolescência.

Durante a análise dos prontuários, foi possível especificar com detalhamento as dificuldades escolares trazidas pelos jovens. Mereceram destaque os seguintes problemas: excesso de faltas às aulas e problemas de relacionamento interpessoal. Em relação a estes, pôde-se evidenciar brigas na escola; isolamento dos colegas ou adesão a grupos marginais; conflitos com professores; dificuldades no relacionamento com os pais e dificuldades dos pais em acompanhar os filhos nas atividades escolares, nas lições de casa e em relação aos comportamentos considerados indisciplinados. Também foram encontradas lições incompletas sem nenhuma observação por parte do professor; lições apenas vistadas pelo professor, mas sem a adequada correção, levando à fixação do erro; defasagem de conteúdo em relação à série que cursam, como, por exemplo, dificuldade em leitura, compreensão e interpretação de textos simples; dificuldade em relação à escrita, especialmente aos aspectos convencionais da escrita, como ortografia e pontuação; dificuldades de expressão do pensamento, tanto oralmente quanto pela escrita; dificuldades em relação às quatro operações, à organização, ordenação, seriação, classificação, organização tempo-espaço, entre outros problemas.

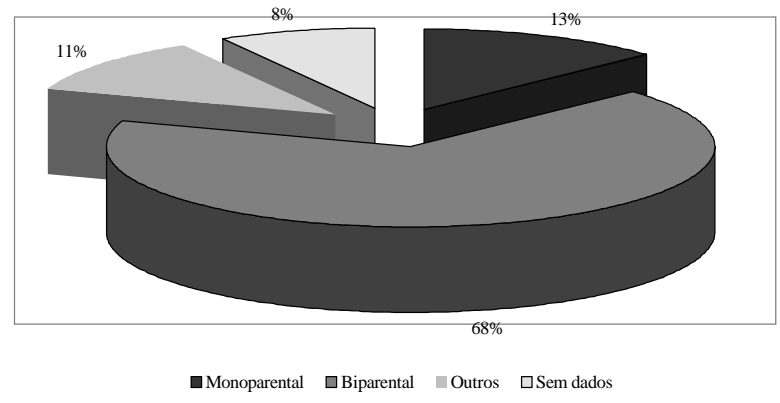

Figura 2: Tipo de família dos pacientes encaminhados para atendimento no serviço de Psicologia do Centro de Atendimento e Apoio ao Adolescente (CAAA - 1997 a 2000), da UNIFESP/EPM. 
Pela Figura 2 pode-se observar que a maioria dos adolescentes (de ambos os sexos) era proveniente de famílias biparentais (68\%), isto é, moravam com ambos os pais. Cabe ressaltar que os procedentes de família monoparental, num total de $11 \%$, moravam com a mãe.

Em relação à fonte de encaminhamento para o serviço de Psicologia do CAAA, o hebeatra (pediatra ou clínico geral com especialização em atendimento a adolescentes) foi o profissional que mais encaminhou pacientes, num total de $50 \%$ dos casos (Figura 3).

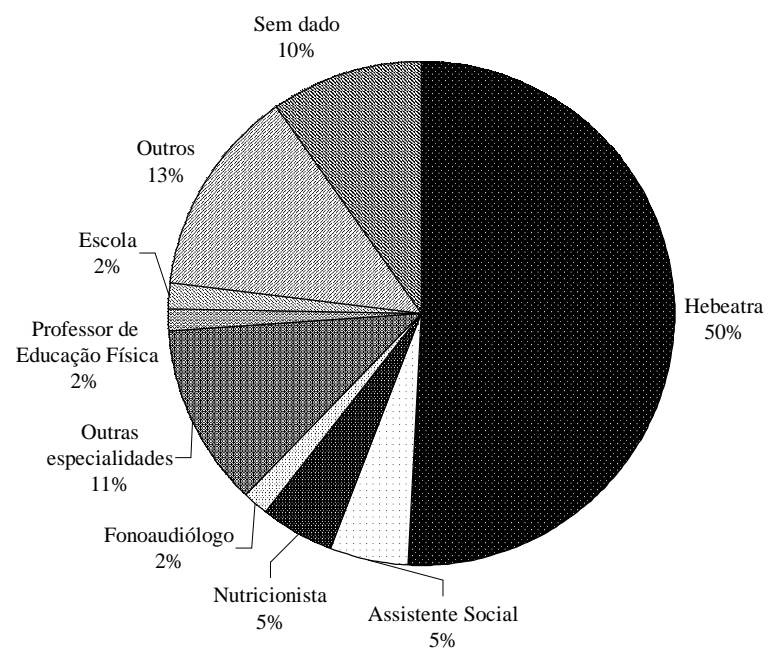

Figura 3: Fonte de Encaminhamento dos pacientes para o serviço de Psicologia do Centro de Atendimento e Apoio ao Adolescente (CAAA - 1997 a 2000), da UNIFESP/EPM.

\section{DISCUSSÃO}

A rotina do CAAA exige que todos os adolescentes matriculados no setor passem em primeira consulta com o hebeatra (pediatra especialista em adolescência). Este motivo explica por que a maioria dos pacientes da Psicologia foi encaminhada por este profissional. Cabe ao hebeatra, neste tipo de rotina, detectar a necessidade do adolescente de receber ajuda psicológica. Portanto, é muito importante que o psicólogo trabalhe em harmonia com o hebeatra, a fim de facilitar o encaminhamento do adolescente ao serviço de Psicologia, e que o hebeatra tenha conhecimento do tipo de problemática que o serviço de Psicologia atende.

Diversos outros estudos (Carvalho \& Térsis, 1989; Yehia, 1994) identificaram o médico como principal fonte de encaminhamento para os serviços de Psicologia. Vazquez (2001) considera o pediatra o único profissional que pode acompanhar o desenvolvimento do indivíduo, do neonato ao adolescente tardio. Por isso é importante que, durante a consulta médica, haja espaço para outras questões, fora a saúde física, como problemas de aprendizagem, problemas de comportamento ou outros sintomas físicos.

Comportamentos problemáticos, como o comportamento anti-social, o insucesso acadêmico, o comportamento sexual de risco, a drogadição, o abuso de álcool e tabaco, estão inter-relacionados e fazem parte do rol de queixas que motivam a consulta ao hebeatra. Este profissional, com uma visão integral do ser humano, tem maior possibilidade de perceber comportamentos desviantes e atuar precocemente, quando não preventivamente, servindo de ponte entre o paciente e outros profissionais.

Como em outros estudos (Carvalho \& Térsis, 1989; Bernardes-da-Rosa, Garcia \& Silvares, 2000), não houve diferença em relação ao sexo dos pacientes atendidos pelo Serviço de Psicologia do CAAA. Este dado precisa ser melhor investigado, visto haver mais meninas matriculadas no CAAA que meninos.

Quanto à idade de encaminhamento do adolescente ao Serviço de Psicologia, observou-se uma prevalência para o início da adolescência. Isto está de acordo com a literatura, quando esta afirma ser este período específico uma época de diminuição da auto-estima, de aumento de conflitos familiares e problemas escolares e, conseqüentemente, de maior necessidade de apoio psicológico (Bee, 1996). Nesta faixa etária, o adolescente ainda está sob os cuidados mais diretos dos pais. Estes se preocupam em levá-lo a atendimentos médicos, já que o jovem, por si mesmo, pode não ser capaz de identificar a necessidade que tem de ajuda especializada. Mais tarde, o adolescente será capaz de ir sozinho, e decidir procurar ajuda ou não, ao exercer sua autonomia.

Chama a atenção, ainda, o grande número de adolescentes com dificuldades escolares, além dos adolescentes com problemas alimentares (acima do peso), enurese noturna, hiperatividade, problemas significativos e indicativos de necessidade de atenção especial. Assim, este estudo corrobora os dados obtidos por Silvares (1998), ou seja, a maior razão de procura de atendimento psicológico são questões escolares, indicando a necessidade de haver, no setor, profissionais com conhecimento sobre o assunto. De igual forma os presentes resultados concordam com os de Graminha e Martins (1994), que observaram uma associação entre dificuldades escolares e outros problemas de ordem emocional/comportamental em $67 \%$ das crianças do seu estudo.

Analisando-se o índice de relação série/idade dos adolescentes matriculados no CAAA, observou-se haver muitos adolescentes em defasagem escolar 
(necessitando de ajuda psicopedagógica), não encaminhados ao setor de Psicologia. Dos adolescentes atendidos pelo serviço de Psicologia, somente $85,24 \%$ encontram-se inseridos em escola. Este dado é alarmante se comparado aos da população de 7 a 14 anos da Região Metropolitana de São Paulo, onde 96,8\% estão no Ensino Fundamental. Considerase que tal resultado se deve ao fato de os usuários do CAAA serem de um nível socioeconômico muito baixo, sendo levados a abandonar a escola por diversos motivos.

Segundo Marturano, Magna e Murtha (1993), há uma elevada demanda de atendimento psicológico motivada por queixas de dificuldade na aprendizagem escolar, particularmente no que diz respeito a crianças em fase de alfabetização. O CAAA atende somente adolescentes, e em nenhum dos prontuários pesquisados havia adolescentes freqüentando as duas séries iniciais do Ensino Fundamental. Porém foram encontrados onze adolescentes na terceira e quarta séries. Tal dado constitui um demonstrativo de sérias dificuldades escolares, especialmente em relação à alfabetização, pois a ênfase do conteúdo do primeiro ciclo é o domínio da língua pátria e das operações fundamentais.

Bernardes-da-Rosa, Garcia, Domingos e Silvares (2000) comentam que a automação das habilidades básicas da criança fica debilitada quando ela apresenta dificuldades de audição, fala, leitura e escrita, resultando em rebaixamento de auto-estima, perda de motivação para a aprendizagem e baixa percepção de inadequação social. Segundo essas autoras, além dessas dificuldades que a criança pode apresentar, a depressão, a ansiedade e problemas de adaptação social podem levar ao fracasso escolar. Assim, a superação das dificuldades escolares é de extrema importância para o seu desenvolvimento adaptativo de um modo geral.

O estudo realizado pelas autoras citadas pretendeu caracterizar, do ponto de vista da identificação demográfica, a clientela encaminhada ao serviço de Psicologia de um hospital geral, cuja queixa principal era a de Distúrbio de Aprendizagem. Nosso estudo, ao contrário, não partiu de uma queixa principal; mas, assim como o estudo por elas realizado, também buscou delinear o perfil sociodemográfico do adolescente que é encaminhado ao setor de Psicologia de um hospital-escola. Neste caso, o interesse era saber quais as queixas mais freqüentes nos encaminhamentos, a fim de melhorar a estrutura de atendimento oferecida pelo setor, envolvendo a melhor preparação da equipe de profissionais e a elaboração de programas de atendimento ao adolescente.
Como em todos os outros estudos citados, a queixa mais frequiente detectada neste levantamento referiu-se a problemas escolares. Mesmo que esta não tenha sido a queixa manifesta que motivou a procura ao CAAA pelos adolescentes, estes, em sua maioria, encontravam-se defasados em relação à idade/série escolar e foram encaminhados para psicodiagnóstico e atendimento no setor de Psicologia. Por isso, consideramos muito importante que o setor esteja preparado para lidar com a questão das dificuldades escolares.

Assim, sugerimos que haja, dentro de uma equipe multiprofissional que atende adolescentes, pessoas especializadas em educação, como um pedagogo, um psicopedagogo ou um psicólogo especializado em atendimento escolar, visando a uma melhor atuação frente a este problema, tanto no próprio setor como diretamente nas escolas, de maneira a se possibilitar o atendimento a um maior número de adolescentes com dificuldades escolares. Neste sentido, variações no atendimento oferecido pelo CAAA estão sendo estudadas, tais como o aumento de profissionais da área de Pedagogia e Psicopedagogia e parceria com outras instituições.

Importante, também, é voltar a atenção para a escola com a opção de desenvolver um trabalho com os professores, pelo fato de serem eles os principais estimuladores do processo de aprender e de ser a escola um ambiente específico e propício para a implementação de programas de ensinoaprendizagem. Não podem ser deixadas de lado as observações feitas nos prontuários dos adolescentes atendidos pelo serviço de Psicologia do CAAA especificando a queixa escolar (lições incompletas, sem visto do professor, erradas). As práticas escolares também devem ser objeto de investigação e intervenção da Psicologia (Cabral e Sawaya, 2001), pois são vários os protagonistas (aluno, pais, professor, equipe técnica) e as circunstâncias presentes no processo ensino-aprendizagem. Não se pode focar apenas o adolescente.

Estas propostas assemelham-se à que foi desenvolvida por Silvares (1998), com a criação da Sucursal da Clínica-escola, no Departamento de Psicologia Clínica da Universidade de São Paulo, cuja intenção foi inverter o fluxo de atendimento, ou seja, os psicólogos passaram a atender seus pacientes na própria escola de Ensino Fundamental e não na clínica-escola universitária. Esta inversão busca auxiliar uma população que não chega até a clínica, em espaços de atendimento que são cedidos pela comunidade. 
A segunda queixa mais freqüente levantada foi desobediência em casa; diferindo do levantamento efetuado por Aznar Farias e Medeiros (1999), no qual essa queixa apareceu em primeiro lugar.

Sobre o fato de má relação familiar ter sido uma das queixas também muito frequiente, há evidências de que a adolescência seja mais estressante para os pais que para os próprios adolescentes. Bee (1996, p. 321) afirma:

Quase dois terços dos pais percebem a adolescência como o estágio mais difícil da paternidade/maternidade, tanto em virtude da perda de controle sobre o adolescente quanto do medo em relação à sua segurança por sua maior independência.

Lidz (1983) considera que a necessidade de ganhar independência crescente dos pais cria sérias dificuldades para os adolescentes e suas famílias. Papalia e Olds (2000) alertam para o perigo da suposição de que a "rebeldia da adolescência" é normal e necessária, a qual leva muitos pais e professores a acreditar que por si mesmos os adolescentes irão superar essa fase, deixando de reconhecer quando um jovem está apresentando comportamentos de risco e necessita de ajuda.

A quantidade de tempo que os jovens passam com os pais diminui drasticamente na adolescência. Segundo Papalia e Olds (2000), os adolescentes sentem-se mais felizes, livres e motivados quando estão com amigos, em contraste com a família, onde a atmosfera tende a ser mais monótona e séria.

Maldonado, Gonzáles e Castro (1999), em um estudo com adolescentes de 14 a 19 anos, observaram que eles evitavam passar o tempo junto a seus pais, pois se sentiam criticados, desvalorizados e incompreendidos.

Para Kimmel e Weiner (1998, p. 235), "O crescimento consiste em aprender a ser física e psicologicamente independente dos pais". Parece que esse impulso para a autonomia, na adolescência, manifesta-se num aumento dos conflitos entre pais e filhos. Nesta fase pode ocorrer uma acentuação de pequenas desavenças ou conflitos acerca de questões cotidianas, como regras, vestimentas, saídas e tarefas domésticas.

Observa-se ainda grande dificuldade dos pais em utilizar estratégias eficazes na educação de seus filhos, além de dificuldades com relação a entenderem que seus filhos estão crescendo e por isso necessitam de outros tipos de abordagem educativa, além de maior liberdade. Nesse sentido, cabe ao CAAA pôr à disposição dos pais programas de orientação sobre como lidar com seus filhos, para que possam compreender que o crescimento consiste em aprender a ser independente dos pais e de outros adultos significativos. Ao se compreender que o adolescente precisa de liberdade para ser ele mesmo, escolher seus amigos e preservar a intimidade de seus pensamentos e sentimentos, entende-se que ele não luta contra os pais, mas a favor de seu crescimento. Berk (1999) comenta que em famílias pequenas o índice de ansiedade nos filhos é mais comum, pois os pais tendem a pressioná-los mais. Já em famílias maiores, com muitos filhos, a supervisão dos pais é diminuída e há uma tendência para maior número de comportamentos anti-sociais dos filhos.

Observou-se que a maioria dos clientes atendidos pelo Serviço de Psicologia do CAAA é proveniente de famílias biparentais, totalizando $68 \%$. Somente $11 \%$ eram provenientes de famílias monoparentais. A literatura indica crianças provenientes de famílias monoparentais como grupo de risco para o desenvolvimento de psicopatologias. O fato nos leva à seguinte reflexão: estaria a organização institucional horário de atendimento, localização da instituição... servindo como empecilho para o atendimento a adolescentes provenientes de famílias monoparentais ou com ambos os responsáveis trabalhando fora? Pode-se pensar que sim, já que o atendimento é diurno e o cuidador não tem possibilidades de trazer o adolescente para ser atendido, acabando por este ser excluído da instituição antes mesmo de nela ingressar. O dado de que, nas famílias biparentais, a mãe é a responsável que traz o adolescente ao CAAA e não trabalha, salvo raras exceções, corrobora esta idéia de que a instituição, mesmo não querendo, acaba por excluir quem dela mais necessita. Arcaro e Mejias (1990) já falavam ser necessário tornar a assistência mais acessível e adequada à clientela, buscando diversas estratégias que possam abranger toda a problemática apresentada pelos clientes, não só a emocional, como também a social. Assim, considerase também importante que haja, num setor que atende adolescentes, atendimentos compatíveis com as atividades dos adolescentes e espaço para a orientação de pais com horários que lhes sejam acessíveis.

Um estudo realizado por Costa, Schoen-Ferreira e Silvares (2002), na triagem do CAAA, encontrou $11 \%$ de adolescentes com enurese. Deste modo, o Serviço de Psicologia do CAAA já se mobilizou para ter um serviço específico para esta problemática.

Outro problema crescente, atualmente, é a obesidade. $\mathrm{Na}$ adolescência, um em cada quatro indivíduos tem a doença. $\mathrm{O}$ adolescente que necessita desse tratamento encontra no CAAA ajuda especializada, em um trabalho multidisciplinar que 
envolve não só o nutricionista ou psicólogo, mas também outras especializações, como Educação Física, Medicina e Fisioterapia.

\section{CONCLUSÃO}

O atendimento ao adolescente possui características específicas que não devem ser ignoradas, especialmente do ponto de vista do atendimento psicológico. $\mathrm{O}$ adolescente pouco adoece, porém apresenta uma maior preocupação em relação às mudanças de comportamento, inclusive comportamentos de risco. Daí a importância de haver profissionais de Psicologia atuando em equipes que atendem adolescentes. $\mathrm{O}$ trabalho interdisciplinar constitui-se em um modelo eficiente para o seguimento da pessoa em desenvolvimento, privilegia a prevenção e permite o diagnóstico precoce, propiciando um desenvolvimento harmonioso.

Nessa discussão, identificamos áreas em que o profissional que atende adolescentes precisa de maior aprofundamento para melhor atender sua clientela.

\section{REFERÊNCIAS BIBLIOGRÁFICAS}

Arcaro, N.T. \& Mejias, N.P. (1990). A evolução da assistência psicológica e em saúde mental: do individual para o comunitário. Psicologia: Teoria e Pesquisa. 6, 251-266.

Aznar Farias, M. \& Medeiros, E.H. (1999). Atención integral al adolescente: una experiência en la UNIFESP-Brasil. III Congreso Internacional de Psicología y Educación, Santiago de Compostela, Espanha. Orientación e intervención pscicopedagógica. Madrid: Distribuidora SEC. Vol 1, 220221.

Bee, H. (1996). A Criança em desenvolvimento ( $7^{\mathrm{a}}$ ed.). Porto Alegre: Artes Médicas.

Berk, L.E. (1999). Desarrollo del niño y del adolescente. Madrid: Prentice Hall.

Bernardes-da-Rosa, L.T., Garcia. R.M., Domingos, N.A.M. \& Silvares, E.F.M. (2000). Caracterização do atendimento psicológico prestado por um serviço de psicologia a crianças com dificuldades escolares. Estudos de Psicologia. 17, 5-14.

Cabral, E. \& Sawaya, S.M. (2001). Concepções e atuação profissional diante das queixas escolares: os psicólogos nos serviços públicos de saúde. Estudos de Psicologia (Natal). 6, 143-155.

Carvalho, R.M.L.L. \& Térsis, A. (1989). Caracterização da clientela atendida na clínica psicológica do Instituto de Psicologia da PUCCAMP. Estudos de Psicologia. 6, 94110.

Costa, N.J.D., Schoen Ferreira, T.H. \& Silvares, E.F.M. (2002/setembro). Enurese noturna na adolescência: relevância da investigação em instituição pública de saúde [painel]. Trabalho apresentado no I Congresso Brasileiro de Psicologia: Ciência \& Profissão, São Paulo.

Dios, V.C. \& Silvares, E.F.M. (1993). Conhecer para que se possa atuar: caracterização da clientela infantil de um hospital-escola de São Paulo [Resumo]. Trabalho apresentado na XXIII Reunião Anual de Psicologia Social (p. 170). Universidade de São Paulo, Campus Ribeirão Preto.

Graminha, S.S.V. \& Martins, M.A.O. (1989). Estruturação e implantação de um novo modelo de inscrição e triagem de casos para o atendimento psicológico infantil existente na universidade [Resumo]. Em Sociedade de Psicologia de Ribeirão Preto (Org.), Programa e Resumos. XIX Reunião anual de Psicologia (p. 258). Ribeirão Preto: SPRP.

Graminha, S.S.V. \& Martins, M.A.O. (1994). Dificuldades de aprendizagem escolar: um estudo de problemas associados [Resumo]. Em Sociedade de Psicologia de Ribeirão Preto (Org.), Programa e Resumos. XXIV Reunião anual de Psicologia (p. 258). Ribeirão Preto: SPRP.

Graminha, S.S.V., Santos, P.L. \& Brandani, R.C. (1987). Necessidade e incidência de atendimento psicológico ou psiquiátrico em uma amostra representativa de crianças: estudo em função do sexo, idade, série, nível de escolaridade e classe social. [Resumo]. Em Sociedade de Psicologia de Ribeirão Preto (Org.), Programa e Resumos. XVII Reunião anual de Psicologia (p. 278). Ribeirão Preto: SPRP.

Hoffman, L., Paris, S. \& Hall, E. (1996). Psicología del desarrollo hoy. Madrid: Mcgraww-Hill.

Instituto Brasileiro de Geografia e Estatística (1999). Anuário Estatístico do Brasil: 1998, vol. 58 (pp.2 - 139). Rio de Janeiro: IBGE

Kimmel, D.C. \& Weiner, I.B. (1998)._La adolescencia: una transición del Desarrollo. Barcelona: Ariel.

Lidz, T. (1983). A pessoa: seu desenvolvimento durante o ciclo vital. Porto Alegre: Artes Médicas.

Maldonado, E.E., Gonzáles, A.G.S. \& Castro, F.V. (1999). Relaciones de los adolescents com sus padres. III Congreso Internacional de Psicología y Educación, Santiago de Compostela. Orientación e intervención psicopedagógica (p. 232). Madrid: SEC.

Martins, M.A.O. \& Graminha, S.S.V. (1994). Extensão da problemática da criança encaminhada para atendimento psicológico [Resumo]. Em Sociedade de Psicologia de Ribeirão Preto (Org.), Programa e Resumos XXIV Reunião anual de Psicologia (p. 264). Ribeirão Preto: SPRP.

Marturano, E.M., Magna, J.M. \& Murtha, P.C. (1993). Procura de atendimento psicológico para crianças com dificuldades escolares: um perfil da clientela. Psicologia: Teoria $e$ Pesquisa. 9, 207-26.

Muñiz, A.M.R. (2001). Pediatria e psicopedagogia: parceria na avaliação do deenvolvimento da criança. Psicopedagogia. 19 (58), 30-32.

Papalia, D.E. \& Olds, S.W. (2000). Desenvolvimento Humano. $7^{\mathrm{a}}$ ed. São Paulo: Pioneira.

São Paulo (1998). Secretaria de Economia e Planejamento. Fundação Sistema Estadual de Análise de Dados - Seade. Vinte anos no ano 2000: estudos sociodemográficos sobre a juventude paulista. São Paulo: Seade. 
Schoen-Ferreira, T.H. (2001). A formação da identidade em adolescentes: um estudo exploratório com estudantes do Ensino Médio, Dissertação de Mestrado não-publicada, Universidade Federal de São Paulo, São Paulo.

Silvares, E.F.M. (1998). Clínicas-escola: novas formas de atendimento psicológico, Tese de livre-docência nãopublicada, Universidade de São Paulo, São Paulo.

Siqueira, M.J.T., Mendes, D., Finkler, I., Guedes, T. \& Gonçalves, M.D.S. (2002). Profissionais e usuárias(os) adolescentes de quatro programas públicos de atendimento pré-natal da região da grande Florianópolis: onde está o pai?._Estudos de Psicologia (Natal). 7, 65-72.

Ungar, M. T. (2000). The myth of peer pressure. Adolescence. $35,167-180$.
Vasquez, H.D. (2001). O pediatra e as dificuldades na aprendizagem: intervenção preliminar. Psicopedagogia. 19 (58), 4-9.

Yehia, G. Y. (1994). Caracterização da clientela que procura o serviço de identificação de superdotados numa clínica psicológica. Estudos de Psicologia. 11, 3-10.

Recebido em 03/05/2002

Revisado em 29/07/2002

Aceito em 30/10/2002 